\title{
Etiology and prognosis of pregnancy-related pelvic girdle pain; design of a longitudinal study
} Janneke M Bastiaanssen*1, Rob A de Bie ${ }^{1}$, Caroline HG Bastiaenen ${ }^{1}$, Annie Heuts ${ }^{2}$, Mariëlle EAL Kroese ${ }^{3}$, Gerard GM Essed ${ }^{4}$ and Piet A van den Brandt ${ }^{1}$

Address: ${ }^{1}$ Department of Epidemiology, Maastricht University, P.O. Box 616, 6200 MD Maastricht, The Netherlands, ${ }^{2}$ Midwifery care, Meerssen, The Netherlands, ${ }^{3}$ Department of Integrated Care, University Hospital Maastricht, Maastricht, The Netherlands and ${ }^{4}$ Department of Gynaecology, University Hospital Maastricht, Maastricht, The Netherlands

Email: Janneke M Bastiaanssen* - J.Bastiaanssen@epid.unimaas.nl; Rob A de Bie - RA.deBie@epid.unimaas.nl; Caroline HG Bastiaenen - CHG.Bastiaenen@epid.unimaas.nl; Annie Heuts - J.Bastiaanssen@epid.unimaas.nl; Mariëlle EAL Kroese - Mkroes@groupwise.azm.nl; Gerard GM Essed - ges@sgyn.azm.nl; Piet A van den Brandt - PA.vandenBrandt@epid.unimaas.nl

* Corresponding author

Published: 03 January 2005

BMC Public Health 2005, 5:I doi: 10.1 I86/I47/-2458-5-I
Received: 23 November 2004

Accepted: 03 January 2005

This article is available from: http://www.biomedcentral.com/I47/-2458/5/I

(C) 2005 Bastiaanssen et al; licensee BioMed Central Ltd.

This is an Open Access article distributed under the terms of the Creative Commons Attribution License (http://creativecommons.org/licenses/by/2.0), which permits unrestricted use, distribution, and reproduction in any medium, provided the original work is properly cited.

\begin{abstract}
Background: Absence of knowledge of pregnancy-related pelvic girdle pain (PPGP) has prompted the start of a large cohort study in the Netherlands. The objective of this study was to investigate the prevalence and incidence of PPGP, to identify risk factors involved in the onset and to determine the prognosis of pregnancy-related pelvic girdle pain.
\end{abstract}

Methods/design: 7,526 pregnant women of the southeast of the Netherlands participated in a prospective cohort study. During a 2-year period, they were recruited by midwives and gynecologists at 14 weeks of pregnancy. Participants completed a questionnaire at baseline, at 30 weeks of pregnancy, at 2 weeks after delivery, at 6 months after delivery and at I year after delivery. The study uses extensive questionnaires with questions ranging from physical complaints, limitations in activities, restriction in participation, work situation, demographics, lifestyle, pregnancy-related factors and psychosocial factors.

Discussion: This large-scale prospective cohort study will provide reliable insights in incidence, prevalence and factors related to etiology and prognosis of pregnancy-related pelvic girdle pain.

\section{Background}

In the Netherlands, little information is available about prevalence, incidence, etiology and prognosis of pregnancy-related pelvic girdle pain (PPGP). It is hypothesized that during pregnancy many women (about 80\%) experience some degree of pain in the pelvic region and/ or the low back and that in some of these patients pain becomes chronic or recurrent. Often, symptoms impact on activities of daily life, hobbies, participation in society, planning of next pregnancies and sometimes lead to a chronic disabling condition with considerable work absenteeism in the future [1]. 
Treatment and indirect costs of these chronic or recurrent patients constitute a considerable burden on health care services, health care insurers and other parties. The total health care expenditures incurred by patients with back pain in the United States in 1998 were approximately $\$ 91$ billion, accounting for about $1 \%$ of the Gross National Product [2]. Van Tulder et al. estimated the costs of back pain for Dutch society in 1991 at $1.7 \%$ of the Gross National Product [3]. These costs consist almost totally of indirect costs (97\%) such as absenteeism and disablement; for that reason chronic back pain can be considered a major economical problem. It is therefore important that PPGP can be diagnosed and treated before PPGP becomes chronic. Consequently, tracking risk factors and characteristics influencing etiology and prognosis of pregnancy-related pelvic girdle pain is important. Absence of knowledge of risk and prognostic factors and the absence of evidence-based treatment strategies about PPGP has prompted the start of a large cohort study in the Netherlands.

In January 2000, the Maastricht PPGP cohort study started. It was established (I) to examine the prevalence and incidence of pregnancy-related pelvic girdle pain (PPGP) during and after pregnancy, (II) to identify risk factors involved in the onset of PPGP and to identify which factors can play an important role in the early detection of PPGP and finally (III) to determine the prognosis of PPGP and to identify prognostic factors. Furthermore, a clinical trial is embedded in this cohort, aimed at studying the effectiveness of a tailor-made treatment program in PPGP after delivery [Bastiaenen et al., treatment, submitted].

\section{Methods/design \\ Design and study population}

In an observational prospective cohort study, etiology and prognosis of PPGP will be studied in 7526 pregnant women. The source population for the study comprises of pregnant women from the southeastern area of the Netherlands.

Both midwives and gynecologists recruit women for the study when pregnant between 10 and 14 weeks. Women are considered eligible if they meet the following inclusion criteria: women are well versed in the Dutch language and at least 18 years. At inclusion, women receive a leaflet containing information about the research project, an informed consent form and a baseline questionnaire. After providing informed consent and filling out the first questionnaire, the women receive a second questionnaire at 30 weeks of pregnancy, a third one at 2 weeks after delivery and a fourth and fifth at 6 months and 12 months postpartum, respectively.
In this study, extensive questionnaires are used with questions ranging from physical complaints (past and present), limitations in activities, restriction in participation, work situation, demographics, lifestyle, pregnancyrelated factors and psychosocial factors. With the help of these questionnaires the prevalence and incidence of PPGP in the Netherlands will be described. In addition, possible risk factors and prognostic factors of PPGP will be examined.

\section{Exposure variables}

In the Maastricht PPGP cohort study several domains of exposure were measured, including individual characteristics, lifestyle, work situation, pregnancy-related factors and psychosocial factors. The majority of factors were assessed with existing, validated questionnaires. The Dutch translation of the Quebec Back Pain Disability Scale (QBPDS) [4] will measure low back functional status [5]. The QBPDS is a 20-item 6-point scale describing activities commonly affected by back pain. This questionnaire is not developed to study a pregnant population and some activities were unsuitable for women who were pregnant or just gave birth. We therefore added a $7^{\text {th }}$ option to the questionnaire, namely "not applicable". We also changed the phrase "because of my back " into "because of my back and/or pelvic pain" in questionnaires. Fear of movement is measured by means of the Dutch translation of the Tampa Scale for Kinesiophobia (TSK) [6,7]. The TSK consists of 17 items; each rated on a 4-point Likert scale. Pain catastrophizing is measured by the Pain Catastrophizing Scale (PCS) [8]. The PCS is a 13item 5-point scale. A woman is said to catastrophize pain, when she views pain as extremely threatening. To measure the experience of negative affect and positive affect we used the 14-item Negative Emotionality Scale (NEM) and the 11-item Positive Emotionality Scale (PEM) [9].

Current mental health was measured by the General Health questionnaire (GHQ). The questionnaire was originally designed as a 60-item instrument, but we used the shortened version GHQ-12 [10].

The perceived stress scale (PSS) was used to measure to assess stress. The PSS is a 14-item instrument with a 5point scale [11].

\section{Outcome measurements}

Pregnancy-related pelvic girdle pain is currently not an entity that can be clearly diagnosed and described. Therefore, Bastiaenen et al. studied separate diagnostic strategies of four international authors in the field of PPGP [Bastiaenen et al., submitted]. They concluded that there was no similarity in the selection of patients with PPGP between the authors. Most of these classification-strategies of PPGP are based on expert-opinions. Therefore, a 


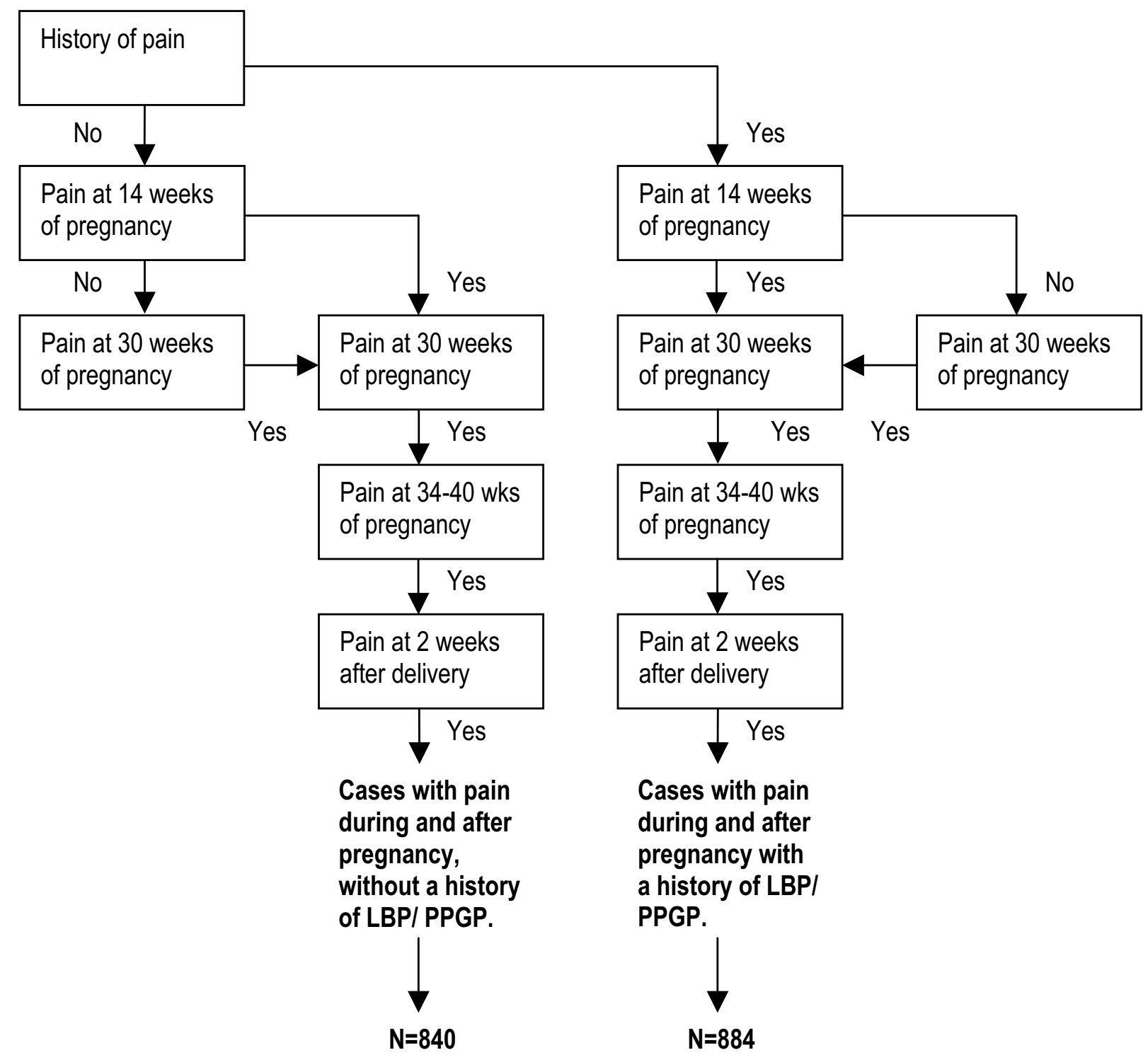

Figure I

Flowchart of pain in the lower back, the buttocks, the symphyses, groins and/or radiation into the legs: description of cases.

possible reason for the lack of similarity in the selection of patients can be that they all select different small parts of the same large patient-group.

Because of the relatively unknown etiology of pregnancyrelated pelvic girdle pain and the lack of an all-embracing definition, we will use an extensive description of PPGP. We expect that during pregnancy almost all women experience some form of pain in the lower back, the buttocks, the symphyses, the groins and/or radiation into the legs.
This pain is probably caused by hormonal and physiological changes which are considered normal during pregnancy. However, some women experience pain in a very early stage of pregnancy while others only experience pain in the final stages of pregnancy. In addition, some women are more limited in their activities (due to pain) than others. This suggests that other factors might influence the hormonal or physiological changes during pregnancy [12]. Most women who had developed PPGP during pregnancy quickly recover after delivery [13]. 
In this study, pain during or after pregnancy is measured by using patients' self-reports. Women with pain can be identified by the question whether they experienced pain in the lower back, the buttocks, the symphyses, the groins or radiation into the legs during or after this pregnancy. To study etiology of PPGP, women who gave a positive answer to this question during this pregnancy were selected.

For the prognosis of PPGP it is important that women have pain that started during pregnancy and persisted after delivery. At several moments during and after pregnancy, experienced pain in the lower back, the buttocks, symphyses, groins or radiation into the legs was measured. The answers to this question were assimilated into a flowchart (Fig. 1).

Based on their self-reports, the women are stratified into a case group without a history of LBP/PPGP or a case group with a history of LBP/PPGP. Some women $(\mathrm{N}=246)$ were not classified into groups for the following reasons; specific disorders of the spine, rheumatism, neurological disorders and cancer. The first group consists of women without a history of LBP/PPGP, but they experience pain during pregnancy and this pain does not disappear until (at least) 2 weeks after delivery. The second group experiences pain during and after pregnancy, but they also have a history of LBP/PPGP. Both groups of cases will be analysed to study the prognosis of PPGP.

Women who experience recurrent pain episodes during pregnancy, that resolve within 2 weeks after delivery, will not be considered cases in the analyses for the prognosis of PPGP. They form a miscellaneous group. However, this miscellaneous group and women who experience no pain after delivery were not excluded from follow-up.

\section{Data analyses}

Participation rates and descriptions of baseline characteristics of the Maastricht PPGP cohort study will be presented. We calculated prevalence rates for PPGP by dividing the numbers of prevalent cases at several moments during pregnancy by the total number of subjects.

\section{Characteristics of the study population at baseline}

Recruitment of women into the study began in November 2000 and ended in November 2002. Approximately 10,850 women were asked to participate in the study by midwives and gynecologist in the southeast of the Netherlands. The locations of the participating midwives and gynecologists are shown in Fig. 2. At the end of the recruitment period 7,526 pregnant women (73.4\%) were willing to participate and were included in the cohort.

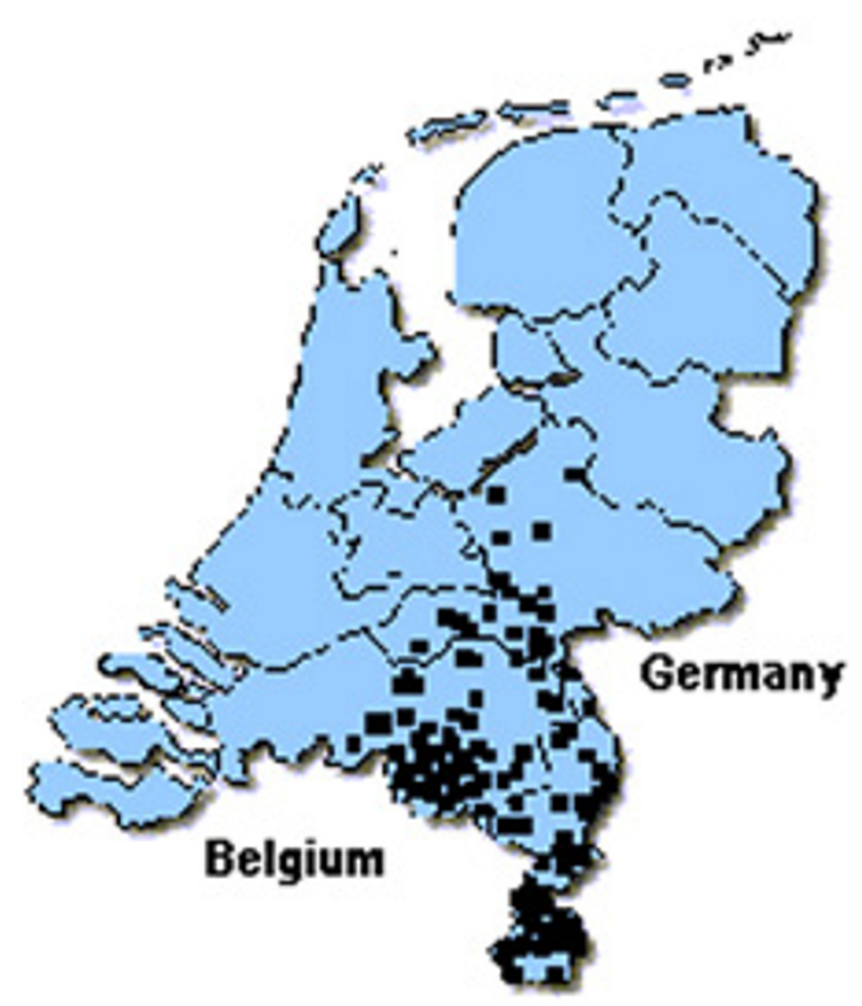

Figure 2

The location of participating midwives and gynaecologists in the Netherlands.

In Table 1 a number of selected characteristics of the study population at baseline are presented, including details of their age, education, BMI, smoking, work and reproductive history. Mean age of the study population is 31.5 years. The educational level of the participants is very high. Approximately $38 \%$ of the participants have had higher vocational or academic education. The use of alcohol during pregnancy is limited. While $44.8 \%$ of the study population did not use alcohol before pregnancy, 91.2\% did not use alcohol during pregnancy. With exception of the country of birth, the study population is heterogeneous with respect to demographics, work status and pregnancy-related factors.

To examine whether the response in our study affected the determinant distributions (e.g. did primarily women in their first pregnancy respond?), a comparison of response rates was carried out. We performed a pilot-study in which data was recorded from April 2001 until November 2001 of every pregnant woman who attended one of the cooperating practices. Information about parity, PPGP during pregnancy, delivery and PPGP after delivery (until 6 weeks) was collected of 283 women (170 participants and 
Table I: Characteristics of the study population $(\mathrm{N}=7526)$ at baseline ( 14 wks pregnancy)

\begin{tabular}{|c|c|c|c|}
\hline Aspect & & & $\%$ \\
\hline Age (yrs) & Mean & & 31.54 \\
\hline \multirow[t]{6}{*}{$N=7523$} & $<=20$ & & 0.4 \\
\hline & $21-25$ & & 5.3 \\
\hline & $26-30$ & & 32.4 \\
\hline & $31-35$ & & 47.8 \\
\hline & $36-40$ & & 12.8 \\
\hline & $>40$ & & 1.2 \\
\hline Country of origin & Netherlands & & 96.5 \\
\hline \multirow[t]{2}{*}{$N=7516$} & $\begin{array}{l}\text { Belgium, Germany, France, Austria, Switzerland, } \\
\text { Luxemburg, Ireland and United Kingdom }\end{array}$ & & 1.9 \\
\hline & Other countries & & 1.6 \\
\hline Education & Primary school & & 0.6 \\
\hline \multirow[t]{8}{*}{$N=7498$} & Preparatory vocational education & & 7.2 \\
\hline & Lower general secondary education & & 6.6 \\
\hline & Vocational education & & 31.9 \\
\hline & Higher general secondary education & & 8.5 \\
\hline & Pre-university education & & 2.3 \\
\hline & Higher vocational education & & 27.7 \\
\hline & Academic education & & 10.3 \\
\hline & Different & & 4.9 \\
\hline BMI before pregnancy & $<18.5$ & Underweight & 3,1 \\
\hline \multirow[t]{3}{*}{$N=7437$} & $18.5-24.9$ & Normal weight & 68,1 \\
\hline & $25.0-29.9$ & Overweight & 20,5 \\
\hline & $>=30$ & Extreme overweight & 8,3 \\
\hline Smoking habits at 14 wks pregnancy & Never & & 59.7 \\
\hline \multirow[t]{2}{*}{$N=7488$} & Ex & & 29.8 \\
\hline & Current during pregnancy & & 10.5 \\
\hline Alcohol-usage (glasses/week) before pregnancy & 0 & & 44.8 \\
\hline \multirow[t]{3}{*}{$N=7482$} & $1-10$ & & 53.5 \\
\hline & $\mathrm{II}-20$ & & 1.6 \\
\hline & $>20$ & & 0.2 \\
\hline Alcohol-usage (glasses/week) during pregnancy & 0 & & 91.2 \\
\hline \multirow[t]{3}{*}{$N=7210$} & $1-10$ & & 8.8 \\
\hline & $11-20$ & & 0.0 \\
\hline & $>20$ & & 0.0 \\
\hline Work (hours/week) & No job & & 13.9 \\
\hline \multirow[t]{5}{*}{$N=7428$} & $1-10$ & & 3.8 \\
\hline & $11-20$ & & 22.9 \\
\hline & $21-30$ & & 21.1 \\
\hline & $31-40$ & & 36.9 \\
\hline & $>40$ & & 1.5 \\
\hline Number of pregnancies & 1 & & 42.3 \\
\hline \multirow[t]{4}{*}{$N=7519$} & 2 & & 36.6 \\
\hline & 3 & & 14.2 \\
\hline & 4 & & 4.6 \\
\hline & $>4$ & & 2.3 \\
\hline
\end{tabular}


Table 2: A comparison between the total Dutch female population and the study population

\begin{tabular}{|c|c|c|c|c|c|c|}
\hline & \multicolumn{3}{|c|}{ Total Dutch population } & \multicolumn{3}{|c|}{ Study population } \\
\hline & Period 2001 & Period 2002 & Period 2003 & $\begin{array}{l}\text { Period 200I } \\
(\mathrm{N}=2892)\end{array}$ & $\begin{array}{r}\text { Period } 2002 \\
(N=3567)\end{array}$ & $\begin{array}{r}\text { Period } 2003 \\
(N=1061)\end{array}$ \\
\hline BMI & $\% *$ & $\% *$ & $\% *$ & $\%$ & $\%$ & $\%$ \\
\hline - Underweight $(<18.5)$ & 5.3 & 4.9 & 3.0 & 2,9 & 3,2 & 3,5 \\
\hline - Normal weight (18.5-24.9) & 70.3 & 71.9 & 71.2 & 66,8 & 68,5 & 70,4 \\
\hline - Overweight (25.0-29.9) & 18.5 & 17.8 & 18.0 & 21,3 & 20,3 & 18,9 \\
\hline - Extreme overweight $(>=30)$ & 5.9 & 5.4 & 7.8 & 9,1 & 8,1 & 7,2 \\
\hline Smoking & $\% *$ & $\% *$ & $\% *$ & $\%$ & $\%$ & $\%$ \\
\hline - Current/before pregnancy & 35.7 & 34.0 & 33.3 & 29.7 & 29.3 & 31.7 \\
\hline \multicolumn{7}{|l|}{ Pregnancy-related factors } \\
\hline \multicolumn{7}{|l|}{ Mean age mother } \\
\hline - Total pregnancies & 30.8 & 30.9 & 31.0 & 31.1 & 31.7 & 32.4 \\
\hline - First pregnancies & 29.2 & 29.2 & 29.3 & 29.6 & 30.2 & 30.9 \\
\hline Child & $\%$ & $\%$ & $\%$ & $\%$ & $\%$ & $\%$ \\
\hline - Boy & 51.2 & 51.3 & 51.4 & 51.0 & 52.2 & 50.5 \\
\hline - Girl & 48.8 & 48.7 & 48.6 & 49.0 & 47.8 & 49.5 \\
\hline Number of pregnancies: & $\%$ & $\%$ & $\%$ & $\%$ & $\%$ & $\%$ \\
\hline - First & 46.3 & 45.8 & 45.5 & 44,6 & $4 I, 0$ & 41.0 \\
\hline - Second & 36.3 & 36.7 & 36.9 & 35,6 & 37,2 & 37.3 \\
\hline - Third & 12.3 & 12.5 & 12.6 & 13,6 & 14,7 & 13.9 \\
\hline - Fourth or more & 5.1 & 5.0 & 5.0 & 6,2 & 7,1 & 7.8 \\
\hline Multiple pregnancy & $\%$ & $\%$ & $\%$ & $\%$ & $\%$ & $\%$ \\
\hline - Twin & 1.9 & 1.9 & 1.8 & 1.0 & 0.9 & I.I \\
\hline
\end{tabular}

* Age-group comparable to study-population

113 non-participants). Results of this pilot-study showed that primipara compared to multiparous women were more willing to participate in the cohort study.

Furthermore, data from the responders in the cohort was compared to available data on pregnant Women in The Netherlands from the "Centraal Bureau voor Statistiek". The results of this comparison are shown in table 2.

Data are presented in 3 separate years to show possible fluctuations. It is noticeable that the mean age of pregnant women is increasing during the 3-year period in the study population and in the total Dutch population. In the study population, pregnant women are slightly older and heavier compared to the total Dutch population. Approximately $34 \%$ of all Dutch women (age 18-45 years), compared to $30 \%$ in the study population, are smoking (see table 2). During pregnancy, $10.5 \%$ of the study population will continue smoking (see table 1 ). In general, data of the study population correspond with data of the total Dutch population.

\section{Prevalence of pregnancy-related pelvic girdle pain during pregnancy}

To determine the prevalence of PPGP during pregnancy, data at baseline (14 wks), 30 weeks of pregnancy and 2 weeks after delivery (information about 34-40 weeks of pregnancy) were used. Almost every woman develops pain in the lower back, the buttocks, the symphyses, the groins or radiation into the legs at some time in their pregnancy. Of the 7527 women, $84 \%$ reported pain in any or all of these areas during pregnancy. Women with a history of LBP/PPGP are more likely to develop PPGP during pregnancy then women without a history of LBP/PPGP (see fig. 3).

\section{Discussion}

In this article, we describe the main characteristics of the Maastricht PPGP cohort study in terms of study design, 


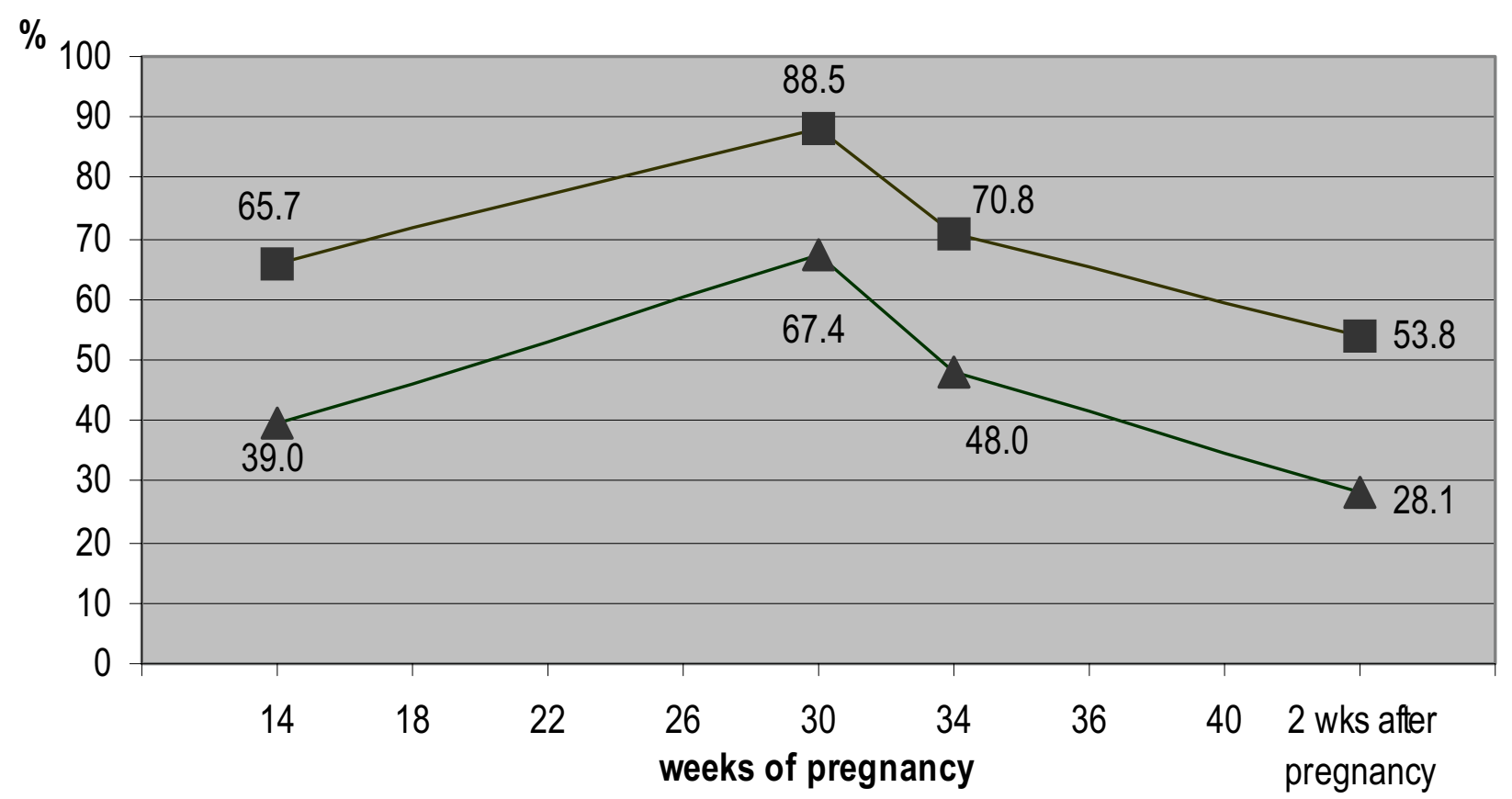

Figure 3

The point prevalence of PPGP during pregnancy for women with $(\mathbf{\square})$ and without $(\mathbf{\Delta})$ a history of LBP/PPGP.

study population, exposure variables and outcome measures. This design, in which both risk factors and outcomes are frequently measured between 14 weeks of pregnancy and 1 year after delivery, enables us to examine the etiology and prognosis of PPGP.

\section{Advantages and disadvantages of the study}

Although a cohort design (even incorporating a randomized controlled trial) has advantages over other epidemiological designs, it poses also a burden on the project in terms of logistics and recruitment. First of all, we are totally dependent on the cooperation and recruiting power of midwives and gynecologists. The number of pregnant women is about evenly divided between the two professions. Although professional workload for midwives in the Netherlands is extremely high, $62 \%$ of the midwife practices took part in this study, recruiting about $90 \%$ of the patients. Whereas $58 \%$ of the hospitals in the recruitment area participate, they only recruit about $10 \%$ of the women. Coordination of the recruitment and frequent staff changes in the hospitals themselves seems to be a key problem.

In etiological research there should be sufficient contrast in exposure. In this study, the study population at baseline is heterogeneous with respect to demographic variables, lifestyle characteristics and work-related factors. However, due to logistic constraints we have restricted the recruiting area to the southeast of the Netherlands, posing questions about the representation of our sample for the whole Dutch population. For instance the number of immigrants is significantly less in the southeast of the Netherlands. However, for future genetically oriented studies, this could be a major advantage. We have shown previously that our sample is slightly different from the national population of pregnant women with regards to several determinants (e.g. age, BMI).

At baseline, 7526 pregnant women participated in our study. This is a response rate of $73.4 \%$. Non-response and loss to follow-up might introduce selection bias in prospective studies. Loss to follow-up, especially in time series designs with repeated measurements, pose threats to representation of the sample. Especially when losses-tofollow-up are connected with negative pregnancy outcomes (miscarriage, birth defects), co-morbidity of the mother or factors predicting for PPGP. To evaluate whether differential loss to follow-up occurs, we will compare the profile of those lost to follow-up with other participants. 
In this study we were able to evaluate if there are significant differences between participants and non-participants. This evaluations shows that primiparous women are more willing to participate in the study compared to multiparous women. We expect that multiparity plays an important role in the etiology and prognosis of PPGP. Therefore, an underestimation of the prevalence of PPGP reported in this study cannot be ruled out. However, the collected sample should be able to provide reliable preliminary insights in incidence and prevalence of PPGP and factors related to etiology and prognosis of PPGP in the Netherlands.

PPGP is a complex syndrome and for a greater understanding of pregnancy-related pelvic girdle pain, future studies should further disentangle the multifactorial etiology and prognosis of PPGP. Future research within the framework of the Maastricht PPGP cohort study will focus on disentanglement of the complex syndrome.

\section{Competing interests}

The author(s) declare that they have no competing interests.

\section{Authors' contributions}

All authors participated in the design of the study. JMB drafted the manuscript with input from the other authors. All authors read, revised and approved the final manuscript.

\section{Acknowledgements}

The Maastricht PPGP cohort study was funded by the Dutch board of health insurance companies. The authors would like to thank the participating midwives and gynecologists as well as all the women who completed the questionnaires. We also would like to thank Conny de Zwart for the logistic assistance.

\section{References}

I. Hansen A, Jensen D, Wormslev M, Minck H, Johansen S, Larsen E, Wilken-Jensen C, Davidsen M, Hansen T: Symptom-giving pelvic girdle relaxation in pregnancy II:Symptoms and clinical signs. Acta Obstet Gynecol Scand 1999, 78: III-II5.

2. Luo X, Pietrobon R, Sun SX, Liu GG, Hey L: Estimates and patterns of direct health care expenditures among individuals with back pain in the United States. Spine 2004, 29:79-86.

3. van Tulder MW, Koes BW, Bouter LM: A cost-of-illness study of back pain in The Netherlands. Pain 1995, 62:233-40.

4. Kopec JA, Esdaile JM, Abrahamowicz M, Abenhaim L, Wood-Dauphinee S, Lamping DL, Williams JI: The Quebec Back Pain Disability Scale. Measurement properties. Spine 1995, 20:34I-52.

5. Schoppink LE, van Tulder MW, Koes BW, Beurskens SA, de Bie RA: Reliability and validity of the Dutch adaptation of the Quebec Back Pain Disability Scale. Phys Ther 1996, 76:268-75.

6. Ruesink RW, Vlaeyen JWS, Pons C, Heuts PHTG: Bewegingsvrees bij aspecifieke chronische lage rugpijn. Ned Tijdschr Geneeskd 1996, 140:2067.

7. Kori SH, Miller RP, Todd DD: Kinisophobia: a new view of chronic pain behavior. Pain management 1990, Jan/Feb:35-43.

8. Sullivan MJL, Bishop SR, Pivik J: The pain catastrophizing scale: development and validation. Psychol Assess 1995, 7:524-532.

9. Watson D, Clark LA, Carey G: Positive and negative affectivity and their relation to anxiety and depressive disorders. J Abnorm Psychol 1988, 97:346-353.
10. Goldberg DP, Gater R, Sartorius N, Ustun TB, Piccinelli M, Gureje O, Rutter C: The validity of two versions of the GHQ in the WHO study of mental illness in general health care. Psychol Med 1997, 27:191-7.

II. Cohen S, Kamarck T, Mermelstein R: A global measure of perceived stress. J Health Soc Behav 1983, 24:385-96.

12. Bastiaanssen JM, De Bie RA, Bastiaenen CHG, Essed GGM, Van den Brandt PA: A historical perspective on pregnancy-related low back and/or pelvic girdle pain. Eur J Obstet Gynecol Reprod Biol in press.

13. Albert H, Godskesen M, Westergaard J: Prognosis in four syndromes of pregnancy-related pelvic pain. Acta Obstet Gynecol Scand 200I, 80:505-10.

\section{Pre-publication history}

The pre-publication history for this paper can be accessed here:

http://www.biomedcentral.com/1471-2458/5/1/prepub

\section{Publish with Biomed Central and every scientist can read your work free of charge}

"BioMed Central will be the most significant development for disseminating the results of biomedical research in our lifetime. "

Sir Paul Nurse, Cancer Research UK

Your research papers will be:

- available free of charge to the entire biomedical community

- peer reviewed and published immediately upon acceptance

- cited in PubMed and archived on PubMed Central

- yours - you keep the copyright

Submit your manuscript here:

http://www.biomedcentral.com/info/publishing_adv.asp
BioMedcentral 